\title{
A INFLUÊNCIA DOS ATOS NA (RE)CONSTRUÇÃO DA IMAGEM
}

\author{
Bruna WysockI
}

\begin{abstract}
Resumo: $O$ presente trabalho tem por proposta analisar a influência dos atos na construção ou reconstrução da imagem de um interlocutor, durante uma interação verbal, a partir das concepções de auditório e orador estudadas por OlbrechtsTyteca e Perelman (2002) e do conceito de construção da imagem pública desenvolvido por Goffman (2004).
\end{abstract}

Palavras-chave: interação; discurso; entrevista; imagem

\section{Introdução}

Diferentes indivíduos numa interação verbal desempenham representações ou papéis sociais os quais denominamos imagem pública. Numa interação verbal, os participantes possuem informações iniciais uns dos outros, que promovem a definição da situação e o planejamento de como agirem para obterem a resposta desejada, em relação as suas expectativas. Essas informações iniciais compõem uma imagem prévia associada aos atos do interlocutor e podem ou não ser modificadas por novos atos. Consideramos ato qualquer modo de expressão transmitido por símbolos verbais ou emitido por ações (Goffman, 2004).

Para a análise, selecionamos alguns trechos de uma entrevista televisiva gravada em 1998, em que o entrevistado Fernando Collor de Melo tenta reconstruir sua imagem associada a episódios desvalorizados socialmente, decorrentes do impeachment no ano de 1992. A partir das perguntas formuladas pelos adolescentes que participavam da platéia, verificamos a relação entre a pré-imagem de Collor formulada pelos entrevistadores e a pressuposição de seus atos como condição para a reconstrução de sua imagem.

A aproximação de valores reconhecidos por todos, como justiça e exercício da democracia; a utilização do argumento de autoridade e a busca de semelhanças com o seu público serão estratégias utilizadas por Collor na tentativa de reconstrução de sua imagem, associada a atos desvalorizados socialmente.

Professora da Rede Municipal de Ensino de São Paulo. Mestre em Língua Portuguesa. FFLCH/USP. 


\section{A interação entre orador e auditório}

Através da argumentação o orador procura obter ou aumentar a adesão do auditório às teses defendidas (Olbrechts-Tyteca e Perelman, 2002) e para isso ele precisa considerar o espírito crítico de seu público, ou seja, é necessário conhecê-lo, saber quais são seus valores e qual a possível imagem que esse possui do orador.

Assim, o auditório pode influenciar o comportamento e a argumentação do orador, pois é preciso adaptar o discurso ao seu auditório para construir, reconstruir ou manter uma imagem confiável de sua pessoa, considerando crenças e valores atribuídas àqueles que o ouvem. Logo, um argumento pró pode tornar-se contra, se não dispormos de uma imagem adequada de nosso auditório.

Para iniciar uma argumentação é necessária uma pré-disposição dos interlocutores para determinarem um acordo: "Em nosso mundo hierarquizado, ordenado, existem geralmente regras que estabelecem como a conversa pode iniciar-se, um acordo prévio resultante das próprias normas da vida social" (Olbrechts-Tyteca e Perelman, 2002:17). Esse acordo estará presente tanto no início quanto no desenvolvimento da argumentação e estará ligado ao que é presumidamente admitido pelos ouvintes, ou seja, o orador precisa ter em mente um auditório que partilhe dos mesmos valores.

O auditório torna-se uma construção do orador e sua argumentação fundamenta-se nessa representação de seus ouvintes. Assim, o orador constrói sua imagem a partir da imagem que ele faz de seu auditório. A idéia prévia que se tem do orador e a imagem construída através de seu discurso precisam estar de acordo com valores reconhecidos socialmente, relacionadas a modelos culturais preexistentes.

\section{A construção e/ou reconstrução da pessoa conforme seus atos}

Toda argumentação pressupõe um acordo entre orador e auditório, sobre um determinado número de dados podendo ser fatos, hierarquias, verdades, estruturas do real, presunções ou valores, enfim, um conjunto de crenças comuns denominado lugares (no sentido de lugar-comum) e que permitem argumentar com melhor eficácia ou não.

A imagem de uma pessoa pode ser construída ou reconstruída ao considerarmos apenas a repetição de um ato e tende a ser objeto de acordos entre grupos e passíveis de revisão. A idéia da pessoa introduz uma impressão de estabilidade ${ }^{1}$ que não está

1 Segundo Mondada e Dubois (2003), os processos de estabilização das categorias evoluem de um nível psicológico, através dos protótipos, a um nível linguiístico, em que encontramos os estereótipos. Para as 
completamente assegurada e ao insistirmos num traço da pessoa considerado permanente, reforça-se a impressão de estabilidade da pessoa inteira.

Existe uma constante interação entre o ato e a pessoa, pois há uma ligação entre a idéia que se constrói de uma pessoa e seus atos: uma pessoa pode ser reconhecida através de seus atos. Porém, essa estabilidade da pessoa opõe-se a sua possibilidade de mudar, de transformar-se e desta forma pode-se deduzir que a pessoa e o ato possuem uma ligação e uma independência relativa.

\section{A influência dos atos na concepção da pessoa e da pessoa nos seus atos}

Segundo Perelman e Olbrechts-Tyteca (2002:339), o ato é definido como "tudo que pode ser considerado emanação da pessoa, sejam eles ações, modos de expressão, reações emotivas, cacoetes involuntários ou juízos".

A imagem de uma pessoa está em constante construção, pois a nossa concepção de pessoa pode mudar de acordo com os atos novos ou antigos que lhes são atribuídos: o ato pode nos obrigar a reconstruir uma concepção de pessoa, a classificá-la numa categoria diferente daquela a qual era atribuída.

Para Olerón (1983), a pessoa do orador pode intervir de duas maneiras: através da imagem que o auditório possui de sua própria pessoa, considerando as características que lhes são atribuídas, ou através do conteúdo de sua mensagem: "o emissor deixa transparecer o que é através do que diz, mesmo quando não procura explicitamente revelar-se ao auditório" (Olerón, 1983:101).

A reação do ato sobre a pessoa geralmente não se limita a uma valorização ou desvalorização desta última, pois muitas vezes o indivíduo serve como intermediário na passagem de atos conhecidos a não conhecidos ou do conhecimento de atos passados à previsão de atos futuros. Geralmente procuram colocar os atos conhecidos e os atos presumidos na mesma categoria. A idéia que se faz da pessoa, ao invés de colaborar para a elaboração de uma conclusão, é o ponto de partida da argumentação e serve para prever atos desconhecidos, interpretar atos conhecidos ou transferir para os atos o juízo sobre a pessoa.

A disposição para aceitar o que se diz antes mesmo de ter sido dito está ligada à representação do locutor, ou seja, suas declarações podem confirmar ou não características que lhes são atribuídas antes de tomar a palavra. Conforme os estudos de Olerón (1983), é possível perceber a influência da imagem do locutor na aceitação de suas afirmações; "quando o que é dito sai da boca de um autor cuja autoridade é reconhecida, esta autoridade transmite-se à coisa dita, que tende a ser ainda melhor aceite.” (Olerón, 1983:101).

O locutor pode fazer uma apresentação diante de seu público, dizendo o que é, com a finalidade de se defender pessoalmente, refutando ataques ou interrogações que não são compatíveis com o que ele é. Ele pode expressar uma emoção, declarando-se indignado

autoras, os protótipos seriam construções psicológicas e individuais que ao serem compartilhadas entre muitas pessoas através da comunicação lingüística, transformam-se em um “objeto socialmente distribuído" (op. cit.) e estabilizado denominado estereótipo. 
e/ou escandalizado com o que disseram sobre a sua pessoa; e/ou pode realizar apelos, requerendo o apoio do público para seus atos.

A concepção da pessoa segundo seus atos é influenciada pelo prestígio, que é uma "qualidade da pessoa que se reconhece por seus efeitos" (Perelman e Olbrechts-Tyteca, 2002:345). Quem possui prestígio desperta nos próximos a vontade de imitá-lo. "Se estas pessoas prestigiosas se mobilizam, tal significa que a causa a que se associaram é boa!" (Olerón, 1983:100).

O prestígio do orador pode crescer ou decrescer de acordo com os efeitos da argumentação, por causa da interação entre a imagem que já se tem do orador e aquela imagem construída pelo seu discurso. Um argumento de prestígio característico é o argumento de autoridade, baseado com maior frequiência na competência do orador.

Sobre a competência, Olerón (1983) a considera essencial na apresentação da mensagem: é mais provável que o orador competente, ou seja, aquele que tem conhecimento do assunto explanado, construa uma argumentação mais eficiente. Desta forma, seu prestígio torna o auditório mais atento.

Contudo, a competência não basta se o público suspeitar que o orador procura influenciar o auditório segundo suas posições ideológicas. A sinceridade demonstrada pelo orador ao apresentar a informação de uma maneira não dissimulada e sua competência determinam a credibilidade de seu discurso. "Com efeito, o orador deve inspirar confiança; sem ela, seu discurso não merece crédito." (Perelman e Olbrechts-Tyteca, 2002: 362).

O orador precisa se adaptar ao auditório e construir uma imagem confiável de sua pessoa, considerando os valores e as crenças que ele atribui ao seu público. Assim, o orador modela sua imagem transmitida de acordo com as representações coletivas que assumem um valor positivo.

\section{Análise do Corpus}

A entrevista analisada foi apresentada ao vivo em agosto de 1998, no Programa Livre, exibido pelo SBT, quando o entrevistado e ex-presidente Fernando Collor de Melo (L1) pretendia candidatar-se novamente à Presidência da República, após ter sido afastado em 1992 de seu cargo político, devido às denúncias de corrupção no governo federal, fato que se tornou histórico na política brasileira. Seu auditório é composto por estudantes de ensino médio e universitários que solicitam ao apresentador e mediador Sérgio Groisman a oportunidade de realizarem perguntas ao entrevistado. Como a entrevista foi transmitida ao vivo, em canal aberto, há também a existência de um auditório universal composto pelos telespectadores. Os participantes do programa que formulam as perguntas serão identificados como (L2).

Ao apresentar-se para seu público (1), o entrevistado constrói uma imagem a partir da pressuposição do valor atribuído pelos entrevistadores aos seus atos no passado:

L1: veja que... eu me apresento hoje diante...diante de todos vocês tendo sido o homem mais investigado desse país o mais humilhado mais xingado o mais achincalhado o mais execrado e seguramente o mais investigado o:: último homem 
público que sofreu alguma coisa parecida em termos de:: de::investigação foi o doutor Getúlio Vargas e que lamentavelmente não suporTOU aquela pressão e deu fim a sua própria vida então hoje eu me apresento tendo sido como disse investigado de cima a baixo (...)

Nesse primeiro exemplo, L1 associa sua imagem à coragem de ter suportado humilhações que outras pessoas, como Getúlio Vargas, não suportariam. Observamos também que o entrevistado realiza sua apresentação como uma defesa pessoal às críticas as quais foi submetido por conta de seus atos, pois as ações cometidas no passado de L1 tornaram-se atos associados à sua imagem e influenciarão toda a argumentação.

Ao repetir por três vezes que foi inocentado (2), o entrevistado reforça um argumento de autoridade utilizado para transmitir ao seu discurso legitimidade e confiabilidade, pois foi julgado e absolvido pela justiça, aquela reconhecida por todos como capaz de julgar alguém: é o lugarcomum encontrado pelo entrevistador.

(2)

L1: (...) quer dizer foram 2 anos de/e meio de investigação em que investigaram TOda a minha vida e todo o resultado dessa investigação foi levado a consideração da mais alta corte de justiça do país que me considerou inocente daquelas acusações e eu me pergunto se hoje há um homem... bom/se nós/se nós estamos vivendo num estado democrático e se nós acreditamos que a justiça cabe julgar as denúncias que são feitas e não ao ao nosso interesse partidário então nós temos que reconhecer que esse é o canal legítimo que nós podemos recorrer dentro de uma democracia para sabermos quem está com a razão e a mais alta corte de justiça do país me declarou inocente dessas acusações eu não sei se houve um homem público brasileiro hoje submetido às mesmas investigações a que eu fui submetido se eles poderiam apresentar ao final dessas investigações esse atestado que me foi dado pela mais alta corte de jusTIça do país de inoCENte daquelas acusações (...)

Já no trecho (3), o entrevistado declara-se injustiçado e indignado com a atitude de seus adversários políticos, pois, segundo ele, houve uma atitude ambígua: se a própria justiça, especializada em condenar ou não pessoas, o declarou inocente, o fato de pessoas sem vínculos com essa justiça praticarem a ação de condená-lo colocaria em dúvida toda a autoridade, competência e prestígio atribuídos pela sociedade ao poder judiciário.

(3)

(L1) (...) fui julgado pelos políticos fui... e fui condenado/fui julgado pela justiça e fui absolvido e o que eu desejo agora é nada mais nada menos que seja dado o diREito ao eleitor de fazer esse julgamento... sem intermediários que votem contra mim ou a favor de mim mas o eleitor representando a sua consciência representando o seu desejo representando as suas expectativas (...) 
Através das expressões "que seja dado o direito" e "fazer esse julgamento" ele transforma a sua candidatura em um "direito" do público. Assim, ele procura aproximar-se dos valores de seu público: o acesso ao direito e o exercício da democracia.

Depois dessa apresentação feita pelo interlocutor L1 para reconstruir sua imagem, ele não consegue a adesão de seu público, pois nas perguntas formuladas por seus interlocutores em (4) e (5), verificamos que seus atos passados são constantemente associados a valores reconhecidos como negativos pela sociedade. No exemplo (4), a entrevistadora expõe em seu discurso a concepção de público transmitida por L1 "o brasileiro não tem memória" ao propor a sua candidatura como um novo ato.

(4)

L2: é... o senhor acredita no dito popular que o brasileiro não tem memória por isso o senhor está se ree/candidatando .... a propósito o senhor tem memória?

(5)

L2: durante as eleições em 89 você falou que o Lula ia confi/confiscar as poupanças e quem acabou fazendo isso um dia depois de ser eleito foi você/cê acha que um candidato pode menTIR para ser eleito ou omitir?

A imagem de L1, influenciada pelos atos passados, é o ponto de partida para pressupor seus atos futuros. Assim, podemos constatar que a imagem do entrevistado adquire uma estabilidade, pois se não foi sincero uma vez, poderá não ser novamente. A pergunta elaborada no exemplo (5) indica uma desvalorização da imagem do entrevistado, que é associada a valores negativos como a mentira e a omissão de informações. Esses valores atribuídos aos seus atos colaboram para pressupor o caráter do entrevistado.

L1 busca a adesão de seu público e a construção de uma imagem confiável, porém, seus atos passados sempre são retomados por meio das perguntas de seus entrevistadores como atos associados à falta de competência, o que contribui para destruir a credibilidade em seu discurso atual.

Porém, assim como os entrevistadores possuem uma imagem do entrevistado, esse também possui uma imagem de seus interlocutores, associando-os a uma categoria social: são jovens que assim como ele, quando pertencente a esse grupo, tinha as mesmas atitudes em situações consideradas parecidas:

(6)

L1: (...) eu se tivesse na posição de vocês naquela oportunidade com aquela campanha da mídia eu seguramente estaria também na ruas pedindo a deposição do presidente que fosse então eu eu entendo perfeitamente tudo que se passou e enTENdo a mobilização que foi feita com os jovens porque eu também já fui mobilizado então ah:: de modo que eu acredito que o povo brasileiro sim tenha memória eu tenho por exemplo memória exata de tudo o que aconteceu desde que eu comecei ah... de... ah::.... na::.... minha faixa dos quatorze quinze dezesseis anos a participar de alguma forma da vida política do meu país (...) 
Ao expor a imagem que faz de seus interlocutores por meio de seu discurso, o entrevistado procura semelhanças "eu se tivesse na posição de vocês" com o intuito de provocar a adesão de seu público pela similitude. Porém, através dessa tentativa de proximidade ele deixa transparecer a sua interpretação para as ações do jovem: "porque eu também já fui mobilizado". No exemplo (6), a entrevistadora indica a imagem transmitida por Collor a respeito de seu público: "povo que não tem cultura e não tem educação necessária e é facilmente manipulado".

(L2) é:: eu quero saber se::::assim/ce quer se submeter a um julgamento popular agora né então eu quero saber se você não acha que se o seu poder de persuasão é maior que a capacidade de discernimento do povo que não tem cultura e não tem e/educação necessária pra/e é facilmente manipulado?

A tentativa de influenciar o auditório é percebida no exemplo (7) e a interlocutora atribui a possibilidade de realização do próximo ato de L1 a um valor desprezado pelo público: subestimar "a capacidade de discernimento do povo".

Ao elaborarem suas perguntas, os entrevistadores associam os atos passados de L1 a sua falta de competência e a valores negativos, o que frustra a tentativa do entrevistado de recuperar a sua credibilidade e legitimidade por intermédio de novos atos.

\section{Conclusão}

A realização do presente trabalho permitiu reunir conceitos fundamentais para observarmos, na análise do corpus, as influências do ato de uma pessoa na reconstrução ou construção de sua imagem. Esses atos podem ser tanto ações praticadas pelos interlocutores, como o discurso realizado no momento da interação.

O orador, ao produzir seu discurso, constrói uma imagem de seu auditório e de acordo como é percebido, avalia a imagem provocada no público e trabalha para confirmála, reelaborá-la ou transformá-la de acordo com o seu projeto argumentativo.

Ao iniciar uma argumentação, o orador precisa reconhecer crenças e valores de seu auditório para realizar uma tentativa de adaptação. Porém, o orador pode enfrentar problemas se o auditório possuir uma pré-imagem associada a valores negativos e não admitir a capacidade de mudança das pessoas. A credibilidade do orador, nesse caso, estará comprometida e seus argumentos tendem a transformar-se em contra-argumentos, reforçando ainda mais sua imagem já deteriorada anteriormente.

Desta forma, a imagem que o público faz do orador pode servir para pressupor atos futuros e apesar da tentativa do orador de mostrar competência por meio de seu discurso, sua imagem o prejudicará, se não estiver associada a valores considerados positivos pelo público.

Após a análise dos trechos selecionados, verificamos que o entrevistado, através de seu discurso, tenta dissociar o ato passado de sua pessoa, mas esse propósito não é 
concretizado, devido à preponderância que o ato adquiriu em sua imagem, retomado nas perguntas dos entrevistadores.

\title{
Referências Bibliográficas
}

CHARAUDEAU, Patrick e MAINGUENEAU, Dominique. Dicionário de análise do discurso. São Paulo: Contexto, 2004.

GOFFMAN, Erving. A representação do eu na vida cotidiana. São Paulo: Vozes, 2004.

MONDADA, Lorenza e DUBOIS, Daniele. Construção dos objetos de discurso e categorização: uma abordagem dos processos de referenciação. In: CAVALCANTE, Mônica Magalhães; CIULLA, Alena; RODRIGUES, Bernardete Biasi (Org.). Referenciação. São Paulo: Contexto, 2003, p. 17-49.

MOSCA, Lineide do Lago Salvador (Org.). Retóricas de ontem e de hoje. São Paulo: Humanitas, 2004.

OLÉRON, Pierre. A argumentação. Lisboa: Publicações Europa-América, S/d. [Orig. PUF, 1983].

PERELMAN, Chaïm. Retóricas. São Paulo: Martins Fontes, 1999.

PERELMAN, Chaïm. e OLBRECHTS-TYTECA, Lucie. Tratado da argumentação. A nova retórica. São Paulo: Martins Fontes, 2002.

\begin{abstract}
The purpose of this paper is to analize the acts influences in construction or reconstruction of image between participants during the verbal interaction, considering the conceptions of auditorium and orator studie by Olbrechts-Tyteca e Perelman (2002) and the idea about construction of public image developed by Goffman (2004).
\end{abstract}

Keywords: interaction; discourse; interview; image 